International Journal of Engineering \& Technology, $7(3.21)(2018) 437-440$
International Journal of Engineering \& Technology
SPC
Website: $\frac{\text { www.sciencepubco.com/index.php/IJET }}{\text { Research paper }}$

\title{
Perceived Confidence and Quality: Perception of Employers Towards Fresh Graduates: a Study in Malaysia
}

\author{
Irza Hanie Abu Samah ${ }^{1 *}$, Aidanazima Abashah ${ }^{2}$, Saraih, Ummi Naiemah ${ }^{3}$ \\ ${ }^{1,2,3}$ UniMAP (Irza Hanie Abu Samah) \\ *Corresponding author E-mail: irzahanie@gmail.com
}

\begin{abstract}
Graduates quality has become a major issue recently especially in today's scenario. Graduates quality can be varying when it perceived by employers. Different sector of industry has different standard of quality. The interpretation of employers towards graduates counts the job placement of graduates. It is hard to standardized quality across industries. Several attributes show that competence relatedness and autonomy do influence the quality of graduates. A quantitative method was used in this study for data gathering. All items were using 10point likert scale. The content validity of this questionnaire were reviewed by five human resource professionals, and Cronbach alpha for each item is more than 0.75 which is acceptable. Questionnaires were given to the human resource officers in the company through email. Convenient sampling was applied in this study for data collection. 50 questionnaires were distributed across manufacturing industry and services industry in Malaysia. Using Partial least square to analyze the data, this study found out that competence in communication is the same criteria which majority across industries are seeking upon graduates. Therefore, Industries that involved are manufacturing $(34.38 \%)$ and services $(65.63 \%)$. Measurement model and structural model were assessed to see the relationship. It shows that perception on competence has most influenced towards quality ( $\mathrm{AVE}=0.849, \mathrm{R} 2=0.734=\mathrm{Q} 2=0.443$ ). This study concludes that employers around the world are looking at similar attribute on graduate's competence. This study also warrants a future research, whereby researcher could get more sample size and by doing sample which involves employers, graduates and educators.
\end{abstract}

Keywords: Graduates; Quality; Confidence; Perception; Interpretation; Industry

\section{Introduction}

Graduates quality has been a word of mouth among majority of employers currently. Employers are seeking for the best candidates to fill up the position in their company regarded that the candidates have what it takes. Several industries have been questionimg on our graduates' quality especially when it comes to soft skill. According to the survey from the Jobstreet in 2016 most of our graduates did not possess good communication skills specifically in English languages. English is not mother tongue language, however, most industries that open its job application is come from multinational companies, and they emphasizing on using English language as a medium. This has put pressure on the graduates themselves and also higher learning institution. However, soft skill along itself does not portray the quality level of graduates. It would be unfair for them if the employers judge on the soft skill alone. After four years in university, soft skill itself does not count as a quality, what matter is the content knowledge and the experience that they have gain, and this we can count as quality. From the employers' viewpoint during the interview session, what they have really seen is actually the confidence level of graduates and that makes the signal whether this graduates have the quality or not to the employers.

The one-time opportunity of interview session is judging the confidence of a graduates and how graduates delivers the speech. Study by Van Laar (1) argues that student scores less in academic achievement will have low self-esteem and study by $\mathrm{Yu}$, Chan, Cheng, Sung, \& Hau (2) finds out that boys who have high aca- demic achieving had higher self-esteem. These studies mention that student who academically high had higher self-esteem and student who is academically low having low self-esteem. However, in Malaysia, skeptical thinking about people active outside academic example sport is still stand firm. They have the perception that sport participation gives negative impact on academic. Student who actively engaged in sport they might have high selfconfidence but low academic achievement whereas student who less participate in sport they might have high academic achievement and less confidence. Culturally, this says have been a path that leads parenting life and discouraging parent and student to involve in sport. This makes a serious conclusion that students whose high in self-confidence is actively participated in activities during university years (1) and yet their academic achievement is on moderate level, compared to nerdy student who possess high academic achievement and less participated in activity. This perception was supported by Santucci (3) whereby student who actively engaged in sport they show low academic achievement because involving in sport requires time, energy and accessibility to other resource which has reduced the time for student to allocate in studying and use their mental capacity to its fullest. Therefore, in Malaysian context for content wise of graduates, employers could misjudge the quality of the student. Hence, this study investigated the employers' perception on graduates' confidence and its relationships to quality. 


\section{Literature Review}

Quality has brought a different meaning for different people and profession and it measures differently. Graduates quality can be measured by the employers through professionalism, perspective and confidence (4). According to Anho (5), there were 20 lists of quality being evaluated by the employers towards graduates which are analytical skill, communication, commitment to duty, critical thinking, decision making, completion of projects, entrepreneurship, human relation, information technology, initiatives, manipulative skill, numeracy, problem solving ability, output, resource management, risk management, self-directed learning, supervisory ability, maintenance and work ethics, the result form this study mentioned that private perceived graduates quality were higher than public sector perceived graduates quality in Nigeria. Contrary, In Malaysia graduate quality have been perceived badly by private sector according to the report of Jobstreet 2016. Graduate in Malaysia have been perceived less confidence, less fluent in English, yet they demand for unrealistic salary once they are graduated. This is because they were comparing the education level with the older generation. It is undeniable that older generation have lesser percentage of degree holder. During that time, those degree holder get paid high salary for degree holders. It became worsts when students nowadays expect the same value of what older generations gets for their salary. What our graduates' misses are, nowadays Malaysia have produced thousands of graduates and this become more difficult for graduated to find a job, and of course they will be competing among them. So, it would be unrealistic if graduates want to get high salary during this time which there were pool of graduates produces in various field during our economic downturn. Employers are now looking for the best candidates. By looking at the confidence level, employers may judge graduates from the interview session and it may affect the perception of quality. The successful of candidates being evaluated is through one-time opportunity via interview session. Even though graduates have good grades, if student does not have confidence it can affect their employment opportunity $(6,7)$.

Study on Middle East and North Africa from Ramadi, Ramadi and Nasr (8) showed that graduates in engineering have less preparedness of employment and there are some areas need to be improved which is communication, time management and continuous learning. Another study by Ali, Kamarudin, Suriani, Saad, \& Afandi (9) found out that requirement needed for accounting students for accounting job are written communication, continuous learning, and decision making skill. Perhaps study conducted by Yusoff et al. (10) emphasizing employers demand on recruiting graduates on capacity to be a leader, ability to undertake problem identification and ability to communicate effectively among engineers' students. Even in various type of employment, the communication element is important to be measured by employers. This shows that employer's expectation on soft skill is generally similar across the industries and this shows that graduates across the globe have similar deficiency which lack of soft skill efficiency. This is no exceptional for Malaysian graduates. This is because, logically think, the report on Jobstreet 2016 reflected that our graduates lack of confidence and communication skill, perhaps those reports were reflected by the employers which only graduates with good academic achievement only were called up for interview. The tendency of good academic achievement graduates to have low self-confidence is high because they were lack to expose themselves in activities during studies as they put more time and effort to study.

Confidence is self-esteem. People need self-esteem in order to achieve the goal. Further understanding about individual achieving the goal can be explained by self-determination theory. Selfdetermination theory explain about the autonomy, competence and relatedness of individual. People always have a goal in life which is the end point of motivation. People who have confidence in life they have control over what situation given is explained by auton- omy. Competence, is to see the competence show by individual in term of their capability in what they are doing especially in interpersonal skill. For relatedness, is the reason people to connect with others and want to established relationship with others. In this context of study, autonomy, competence and relatedness were explained in the context where employers perceived graduates' ability to control their self (anxiety/nerves nous) which resembles "autonomy" during the interview session, "competency" is the communication skill during interview and "relatedness" is graduates ability to establish trust and interest towards interviewer. The perception of employers about graduate's confidence in term of autonomy, relatedness and competence will influence the quality that employers may perceived.

Perception of quality can be affected by the confidence of graduates. Although graduates possess good point average, however if they don't have the confidence level, their name will be eliminated from the list of potential candidates. How employers may respond towards interview session is based on what they perceived. If questions being ask cannot be answered or answers with hesitation, at this point employers may perceive that this candidate has less confidence in terms of autonomy, competence and relatedness. Therefore, it may affect the decision of graduates' quality. Therefore, this research proposed three hypotheses which are: H1: There is a relationship between employers' perception on graduates perceived autonomy and perceived quality.

$\mathrm{H} 2$ : There is a relationship between employers' perception on graduates perceived competence and perceived quality.

H3: There is a relationship between employers' perception on graduates perceived relatedness and perceived quality.

\section{Methodology}

This quantitative study was done using survey questionnaire whereby the independent variables was adopted questionnaire from Broeck, Vanteenskiste, Witte, Soenens, \& Lens (11) to determine the confidence level. This item has been modified to the employers' viewpoint. Example of question which all statements have been changed to "Do you think it is important for graduates be able to feel free to express their ideas and opinion?". All items were using 10-point likert scale. Next, in order to measures quality of graduates, this study has adopted a set of questionnaire which were developed by Hamid, Islam \& Hazilah (12). The content validity of this questionnaire were reviewed by five human resource professionals, and Cronbach alpha for each item is more than 0.75 which is acceptable. This study is to see perception of employers towards graduates' confidence and quality. the questionnaires were distributed among employers which in two different sector of industries namely manufacturing and services. Questionnaires were given to the human resource officers in the company (one representative at any level; executive or manager). which person in charge in recruitment through email with covering letter. Convenient sampling was applied in this study for data collection. 50 questionnaires were distributed across manufacturing industry and services industry in Malaysia. Response rate attainment was $64 \%$. PLS 3.0 were used to analyze the data gathered and explained below.

\section{Result and Findings}

Table 1: Respondents demographic information

\begin{tabular}{|l|l|l|}
\hline \multicolumn{3}{|c|}{ Table 1: Respondents demographic information } \\
\hline Variables & (f) & Percentage (\%) \\
\hline Manufacturing & 11 & 34.38 \\
\hline Services & 21 & 65.63 \\
\hline Gender: & & \\
\hline Male & 15 & 46.88 \\
\hline Female & 17 & 53.12 \\
\hline Years of working experience : & & \\
\hline 5 years or below & 10 & 31.25 \\
\hline 6-10 years & 15 & 46.87 \\
\hline 11-15 years & 4 & 12.50 \\
\hline
\end{tabular}


\begin{tabular}{|l|l|l|}
\hline 16 years and above & 3 & 9.37 \\
\hline
\end{tabular}

Based on table 1, demographic profile of respondents shows that the percentage of respondents from manufacturing sector is $34.38 \%$ whereas for services sector is $65.63 \%$. the portion between male and female respondent shows almost proportionate which for male is $46.88 \%$ and for female $53.12 \%$. it shows that company in Malaysia are majority have equally held position in management level between female and male.

Assessment of Measurement Model

Table 2:

\begin{tabular}{|l|l|l|l|l|}
\hline CONSTRUCT & ITEM & LOADINGS & AVE & CR \\
\hline QUALITY & QC2 & 0.781 & 0.683 & 0.959 \\
\hline & QC3 & 0.846 & & \\
\hline & QC4 & 0.971 & & \\
\hline & QC5 & 0.940 & & \\
\hline & QC6 & 0.990 & & \\
\hline & QC7 & 0.992 & & \\
\hline & QT1 & 0.951 & & \\
\hline & QT2 & 0.985 & & \\
\hline & QT4 & 0.988 & & \\
\hline & QT5 & 0.876 & & \\
\hline & QT6 & 0.835 & & \\
\hline AUTONOMY & CA1 & 0.834 & $\mathbf{0 . 8 6 5}$ & $\mathbf{0 . 9 5}$ \\
\hline & CA2 & 0.979 & & \\
\hline & CA3 & 0.971 & & \\
\hline COMPETENCE & CC1 & 0.775 & $\mathbf{0 . 8 4 9}$ & $\mathbf{0 . 9 5 7}$ \\
\hline & CC2 & 0.944 & & \\
\hline & CC3 & 0.974 & & \\
\hline & CC4 & 0.978 & & \\
\hline RELATEDNESS & CR1 & 0.85 & $\mathbf{0 . 5 7 8}$ & $\mathbf{0 . 8 4 4}$ \\
\hline & CR2 & 0.849 & & \\
\hline & CR3 & 0.693 & & \\
\hline & CR4 & 0.625 & & \\
\hline
\end{tabular}

Table 2, indicates loadings of each latent variable. Result shows that all loading is accepted whereby it pass the standard minimum requirement which is $>0.4$ (13). AVE result show that all latent variable for Quality (0.683), Autonomy (0.865), Competence (0.849) \& Relatedness (0.578) display satisfactory convergent validity which the value is more than 0.5 .

Table 3: Fornell \& Lacker Criterion

\begin{tabular}{|l|l|l|l|l|}
\hline Variables & QUAL & AUTON & COM & REL \\
\hline QUALITY & 0.827 & - & - & - \\
\hline AUTONOMY & 0.575 & 0.93 & - & - \\
\hline COMPETENCE & 0.846 & 0.727 & 0.921 & - \\
\hline RELATEDNESS & 0.459 & 0.529 & 0.446 & 0.76 \\
\hline & & & & \\
\hline
\end{tabular}

Table 3, indicates Fornell \& Lacker criterion. Bold numbers on the diagonal shows square root of AVE, where by the bold numbers should be higher than the numbers stated below. Result on table 4, showing discriminant validity. Whereby each construct is not related with other construct.

Table 4: Cross Loading table

Table 4: Cross Loading table
\begin{tabular}{|l|l|l|l|l|}
\hline ITEM & QUAL & AUTON & COMP & REL \\
\hline CA1 & 0.332 & 0.834 & 0.452 & 0.321 \\
\hline CA2 & 0.571 & 0.979 & 0.715 & 0.526 \\
\hline CA3 & 0.629 & 0.971 & 0.784 & 0.569 \\
\hline CC1 & 0.621 & 0.97 & 0.775 & 0.551 \\
\hline CC2 & 0.775 & 0.602 & 0.944 & 0.329 \\
\hline CC3 & 0.854 & 0.595 & 0.974 & 0.404 \\
\hline CC4 & 0.845 & 0.604 & 0.978 & 0.4 \\
\hline CR1 & 0.403 & 0.404 & 0.396 & 0.85 \\
\hline CR2 & 0.44 & 0.437 & 0.446 & 0.849 \\
\hline CR3 & 0.257 & 0.486 & 0.209 & 0.693 \\
\hline CR4 & 0.051 & 0.186 & 0.063 & 0.625 \\
\hline QC2 & 0.781 & 0.443 & 0.657 & 0.158 \\
\hline QC3 & 0.846 & 0.475 & 0.694 & 0.277 \\
\hline QC4 & 0.91 & 0.555 & 0.859 & 0.34 \\
\hline QC5 & 0.806 & 0.406 & 0.609 & 0.407 \\
\hline QC6 & 0.919 & 0.551 & 0.787 & 0.398 \\
\hline QC7 & 0.884 & 0.499 & 0.76 & 0.404 \\
\hline QT1 & 0.683 & 0.473 & 0.609 & 0.288 \\
\hline QT2 & 0.777 & 0.332 & 0.545 & 0.437 \\
\hline QT4 & 0.789 & 0.394 & 0.592 & 0.412 \\
\hline QT5 & 0.845 & 0.531 & 0.771 & 0.517 \\
\hline QT6 & 0.823 & 0.513 & 0.727 & 0.513 \\
\hline Tab 4: & ch & & \\
\hline
\end{tabular}

Table 4: using cross loading to assess discriminant validity, each indicator load higher on its own construct and low with other constructs. This indicate discriminant validity is achieved as construct distinctly different from each other. As base on the measurement model, this model is accepted to be proceed since it pass all the measurement model assessment through AVE, cross loading, composite reliability and also Fornell \& lacker, whereby this model pass all minimum standard required. Next step, in order to measure the relationship between exogenous and endogenous, few test of structural model need to be proceed.

\section{Structural model}

Table 5: Lateral collinearity assessment

\begin{tabular}{|l|l|}
\hline Construct & Quality (VIF) \\
\hline Quality & \\
\hline Autonomy & 2.387 \\
\hline Competence & 2.145 \\
\hline Relatedness & 1.404 \\
\hline
\end{tabular}

Multicolinearity is important to study when there are two variables that are hypothesized to be causally related to measure the same construct. Table 5 measuring lateral collinearity and it indicates that all inner VIF are less than 5 and 3.3 which means multicollinearity is not concern in this study.

Table 6: Hypothesis testing

\begin{tabular}{|c|c|c|c|c|c|c|c|c|c|}
\hline Hypothesis & Relationship & Std beta & Std error & t-value & Decision & $\mathbf{R 2}$ & F2 & Q2 & q 2 \\
\hline $\mathrm{H} 1$ & Autonomy $\rightarrow$ quality & -0.146 & 0.174 & 0.837 & Reject & \multirow[t]{3}{*}{0.734} & 0.034 & \multirow[t]{3}{*}{0.443} & 0.009 \\
\hline $\mathrm{H} 2$ & Competence $\rightarrow$ quality & 0.891 & 0.171 & 5.2 & Supported & & 1.389 & & 0.429 \\
\hline H3 & Relatedness $\rightarrow$ quality & 0.139 & 0.157 & 0.885 & reject & & 0.052 & & 0.013 \\
\hline
\end{tabular}

Table 6 indicate hypothesis testing that developed between construct. Base on the assessment of path coefficient indicates that $\mathrm{t}$ value $>1.645$, significant at 0.05 level only for $\mathrm{H} 2$ (Beta $=0.891$, $\mathrm{p}<0.01)$, whereas for $\mathrm{H} 1$ and and $\mathrm{H} 3 \mathrm{t}$-value $>1.654$ is not significant at 0.05 level. Specifically, predictors of competence $(B=0.891$, $\mathrm{p}<0.01$ ), positively relative with quality which explains $73.4 \%$ of variance quality. therefore, $\mathrm{H} 2$ is supported. The $\mathrm{R} 2$ value of 0.734 is above the value of 0.5 as suggested by Hair et al. (2014) describing moderate level of predictive accuracy. To measure effect size, as suggested by Cohen (14) the values of $0.02,0.15,0.35$ describing as small medium and large effect. As according to table 6 , effect size for competence shows large effect size. In predictive relevance using blindfolding to measure wheth- er model has predictive relevance or not. If the value of Q2 is larger than 0 , the model has predictive relevance for certain endogenous construct $(15,16)$ the value of $\mathrm{Q} 2(\mathrm{Q} 2=0.443)$ is larger than 0 , indicates that the model has sufficient predictive relevance. Furthermore, the result of q2 shows only competence has large effect size. Hence, $\mathrm{H} 1$ and $\mathrm{H} 3$ is rejected.

Competence in term of interpersonal skill has shown major impact towards graduate's quality, therefore, this study was supported by previous study $(5,17)$ which emphasizing on communication skill and interpersonal skill. Hence, the perception of employers on graduates' interpersonal skills are influencing the perceptions of graduates' quality. Therefore, hypothesis 2 is accepted. 


\section{Conclusion}

This study concludes that employers around the world are looking at similar attribute on graduates. Preview of literature by western countries and Asian country found out there is similarities on the perception of employers and what employers expect from graduates. Furthermore, this study supported previous literature whereby the results indicate that competence and quality is highly predicting the model.

The importance of this study is that this study is crucial in order to investigate employers' demand on graduates especially during this high time of economic downturn in Malaysia. By gaining what is the perspective of employers, this result could help most higher learning institution into preparing the syllabus and formulating courses which suit the demand of employers. This study also revealed employers' requirement style for recruiting fresh graduates through times. The study finds out that employers before and now are looking at the same quality. This is supported by study from McMurray et al. (17) whereby employers are seeking for soft skills efficiency which are personal attitude, employability skills, trustworthiness, reliability, motivation, communication skills and willingness to learn. This study warrants a future research, first researcher could get more sample size and by doing sample which involves employers, graduates and educators. This study also suggest that employers might want to use various method during interview session such as psychometric test to the tendency of candidates, IQ test to see which intelligence candidates more prone to, and also fast presentation helps employers to identify the personality, confidence and attitude. Although this method might be time consuming but it will be worthy for organization later on in finding graduates that will suit most with organization's value and culture

\section{Acknowledgement}

This research work is supported by the short term grant (19/12/1618/1217) by Universiti Malaysia Perlis.

\section{References}

[1] Van Laar C. The paradox of low academic achievement but high self-esteem in African American students: An attributional account. Educational psychology review. 2000;12(1):33-61.

[2] Yu C, Chan S, Cheng F, Sung R, Hau KT. Are physical activity and academic performance compatible? Academic achievement, conduct, physical activity and self-esteem of Hong Kong Chinese primary school children. Educational Studies. 2006;32(4):331-41.

[3] Santucci A. The effect of sports participation on gas: a conditional quantile regression analysis: The University of California; 2012.

[4] Sole G, Claydon LS, Hendrick P, Hagberg J, Jonsson J, Harland T. Employers' perspectives of competencies and attributes of physiotherapy graduates: an exploratory qualitative study. 2012.

[5] Anho JE. An evaluation of the quality and employability of graduates of Nigeria Universities. African Journal of Social Sciences. 2011;1(1):179-85.

[6] Kelley CA, Gaedeke RM. Student and employer evaluation of hiring criteria for entry-level marketing positions. Journal of Marketing Education. 1990;12(3):64-71.

[7] SHI H-m, LIU J-h. Employment Confidence of Undergraduate and Its Influencing Factors [J]. Market \& Demographic Analysis. 2006;2:012.

[8] Ramadi E, Ramadi S, Nasr K. Engineering graduates' skill sets in the MENA region: a gap analysis of industry expectations and satisfaction. European Journal of Engineering Education. 2016;41(1):34-52.

[9] Ali IM, Kamarudin K, Suriani NA, Saad NZ, Afandi ZAM. Perception of employers and educators in accounting education. Procedia Economics and Finance. 2016;35:54-63.

[10] Yusoff YM, Zaharim A, Omar MZ, Mohamed A, Muhamad N, Mustafa R, editors. Employers' selection skills in recruiting fresh engineering graduates. Engineering Education (ICEED), 2009 International Conference on; 2009: IEEE

[11] Broeck A, Vansteenkiste M, Witte H, Soenens B, Lens W. Capturing autonomy, competence, and relatedness at work: Construction and initial validation of the Work-related Basic Need Satisfaction scale. Journal of Occupational and Organizational Psychology. 2010;83(4):981-1002.

[12] Hamid MSA, Islam R, Hazilah AMN. Malaysian graduates' employability skills enhancement: an application of the importance performance analysis. Journal for Global Business Advancement. 2014;7(3):181-97.

[13] Hulland J. Use of partial least squares (PLS) in strategic management research: A review of four recent studies. Strategic management journal. 1999:195-204.

[14] Cohen J. Statistical power analysis for the behavioral sciences Hilsdale. NJ: Lawrence Earlbaum Associates. 1988;2.

[15] Joe Jr F, Sarstedt M, Hopkins L, Kuppelwieser VG. Partial leas squares structural equation modeling (PLS-SEM): An emerging tool in business research. European Business Review. 2014;26(2):106-21.

[16] Fornell C, Cha J. Partial least squares. Advanced methods of marketing research. 1994;407(3):52-78

[17] McMurray S, Dutton M, McQuaid R, Richard A. Employer demands from business graduates. Education+ Training. 2016;58(1):112-32 